\title{
P207: A cluster of panton- and valentin- producing Staphylococcus aureus infection at a departmental hospital in Benin: possible association with consumption of contaminated food
}

\author{
TA Ahoyo $^{1 *}$, C Le Brun ${ }^{2}$, M Makoutode ${ }^{3}$, S Baba-Moussa ${ }^{1}$, Y Piemont ${ }^{21}$, K Dramane $^{1}$, G Prevost $^{21}$, A Sanni ${ }^{1}$ \\ From 2nd International Conference on Prevention and Infection Control (ICPIC 2013) \\ Geneva, Switzerland. 25-28 June 2013
}

\section{Introduction}

A three-month period in 2005, two distinct types of methicillin-sensitive Staphylococcus aureus (one producing of Panton-Valentine leukocidin (PVL) and the other not) were isolated from bronchial specimens of paediatric inpatient unit at the Zou/Collines Departmental Hospital (CHDZ/C), who had been previously cared for by the nurses. The source of outbreak was probably a faulty contamination of specific food consumed by patients.

\section{Objectives}

we aim to determine the source of particular S. aureus strains and possible relationships with hospital environment.

\section{Methods}

An investigation was conducted that involved screening of all inpatients receiving a specific food, hospital environment sampling and the follow-up of cases until the end of hospital stay. Isolates were identified, tested for antimicrobial susceptibility and analysed for PVL,LukE/ LukD, and enterotoxin A production. Pulse Field Gel Electrophoresis (PFGE) was performed to establish the clonality of the strains.

\section{Results}

A total of 36 infected inpatients with $S$. aureus were identified. Twenty-eight cases of pneumonia were discovered and PVL-producing S. aureus concerned 61\%.
By PFGE an indistinguishable PVL-producing S. aureus was identified in the food served, 28 patients, the keyboard and faucet handles in their respective room. Enhanced hygiene measures, particular hand hygiene, terminated the outbreak.

\section{Conclusion}

Our finding suggest an associated between environmental contamination and patient infection, not limited to the patients' rooms. Transmission of PVL-producing $S$. aureus can be prevented in the hospital by a combination of decontamination of the environment, and the promotion of hand hygiene.

\section{Disclosure of interest}

None declared.

\section{Author details}

${ }^{1}$ Laboratory of Biochemistry and Molecular Biology, Faculty of Sciences and Techniques, University of Abomey, Abomey, Benin. ${ }^{2}$ Institute of Bacteriology, University Hospital, University Louis Pasteur, UPRES EA-3432, Strasbourg, France. ${ }^{3}$ IRSP, University of Abomey, Abomey, Benin.

Published: 20 June 2013

doi:10.1186/2047-2994-2-S1-P207

Cite this article as: Ahoyo et al:: P207: A cluster of panton- and valentinproducing Staphylococcus aureus infection at a departmental hospital in Benin: possible association with consumption of contaminated food. Antimicrobial Resistance and Infection Control 2013 2(Suppl 1):P207. 